\title{
Collaborations Focused on Enhancing Undergraduate Involvement in Remote Sensing Applications to Atmospheric and Earth Science Research
}

This is the author's version of the work. It is posted here for your personal use. Not for redistribution. The definitive Version of Record was published in the in the International Geoscience and Remote Sensing Symposium under Institute of Electrical and Electronics Engineers (IEEE).

(C) 2006 IEEE. Personal use of this material is permitted. Permission from IEEE must be obtained for all other uses, in any current or future media, including reprinting/republishing this material for advertising or promotional purposes, creating new collective works, for resale or redistribution to servers or lists, or reuse of any copyrighted component of this work in other works.

L. Hayden and A. Omar, "Collaborations Focused on Enhancing Undergraduate Involvement in Remote Sensing Applications to Atmospheric and Earth Science Research," 2006 IEEE International Symposium on Geoscience and Remote Sensing, Denver, CO, 2006, pp. 2010-2012. doi: $10.1109 /$ IGARSS.2006.520

URL: http://ieeexplore.ieee.org/stamp/stamp.jsp?tp=\&arnumber=4241667\&isnumber=424114 $\underline{6}$

Keywords:

Aerosols; atmospheric temperature; ocean temperature; oceanographic regions; physics education; remote sensing; wind; remote sensing applications; atmospheric research; Earth science research; undergraduate physics; NASA Langley Research Center; Hampton University; Virginia; Elizabeth City; State University; North Carolina; Office of Naval Research; Sounding of the Atmosphere using Broadband Emission Radiometry; SABER instrument; Thermosphere Ionosphere Mesosphere Energetics and Dynamics; TIMED satellite; Mesosphere Lithosphere Thermosphere Ionosphere region; infrared limb emission; scatter lidar equation; tropospheric aerosol; stratospheric aerosol; atmospheric temperature measurements; SAGE III limb scattering data; gas profiles; coastal upwelling; wind measurements; sea surface temperatures; Advanced Very High Resolution Radiometer; AVHRR; NOAA Polar Orbiting Environmental Satellites; POES; turbidity; Atlantic Ocean; SeaWiFS ocean color data; chlorophyll concentrations; northwestern Gulf of Mexico; AD 2002; research training activities; Stennis Space Center; Collaboration; Remote sensing; Geoscience; Instruments; Atmosphere; Radiometry; Ionosphere; Satellite broadcasting; Acoustic scattering; Aerosols 
Collaborations Focused on Enhancing Undergraduate Involvement in Remote Sensing Applications to Atmospheric and Earth Science Research

\author{
Dr. Linda Hayden \\ Elizabeth City State University \\ Center of Excellence in Remote Sensing Education and Research \\ Box 672 ECSU 1704 Weeksville Raod \\ Elizabeth City, NC 27909 \\ Phone: 252-335-3696 Fax 252-335-3790 \\ email: haydenl@mindspring.com \\ Dr. Ali H. Omar \\ NASA Langley Research Center \\ Atmospheric Sciences, MailStop 401 A \\ Hampton, VA 23681 \\ Phone: 757-864-5128 Fax: 757-864-7790 \\ email: ali.h.omar@nasa.gov
}

Poster Presentation

Suggested Topic Area: EH02 - Innovations in Remote Sensing Education

Abstract

This paper discusses the mentoring strategies used with groups of undergraduate physics, mathematics and atmospheric science majors to develop their ability to contribute to remote sensing investigations. The projects have been a joint effort of scientist and educator at NASA Langley Research Center, Hampton University in Virginia, Elizabeth City State University in North Carolina, Stennis Space Center, and The Office of Naval Research.

Atmospheric Science investigations have included verification of Sounding of the Atmosphere using Broadband Emission Radiometry (SABER). The SABER instrument is one of the four instruments housed on the Thermosphere Ionosphere Mesosphere Energetics and Dynamics (TIMED) satellite. SABER explores the MLTI (Mesosphere Lithosphere Thermosphere Ionosphere) region of the earth's atmosphere using infrared limb emission to sound the atmosphere. Other Atmospheric Science investigations have included use of a single scatter lidar equation to investigate tropospheric and stratospheric aerosol and temperature measurements derived from the 355 and $532 \mathrm{~nm}$ channels and comparison of the SAGE III limb scattering data to other instruments measuring similar aerosol and gas profiles.

Earth Science Investigations include investigating incidents of coastal upwelling during the summer of 2000 along the northeastern coast of North Carolina (from Cape Hatteras to the Virginia Commonwealth border) by comparing archived in-situ near and offshore wind and temperature measurements with sea surface temperatures deduced from observations by the Advanced Very High Resolution Radiometer (AVHRR) on board several of NOAA's Polar Orbiting Environmental Satellites (POES); Remote sensing investigation of turbidity and water clarity in the Atlantic Ocean with the use of SeaWifs Data during which the frequency and extent of turbidity events in the Atlantic Coast was studied and SeaWiFS Ocean Color data was utilized to generate secchi disk 
depth estimates and; determining the spatial and temporal variability of chlorophyll concentrations in the northwestern Gulf of Mexico during 2002. Techniques for developing the required collaborations, student selection and organization of research training activities are described in this paper.

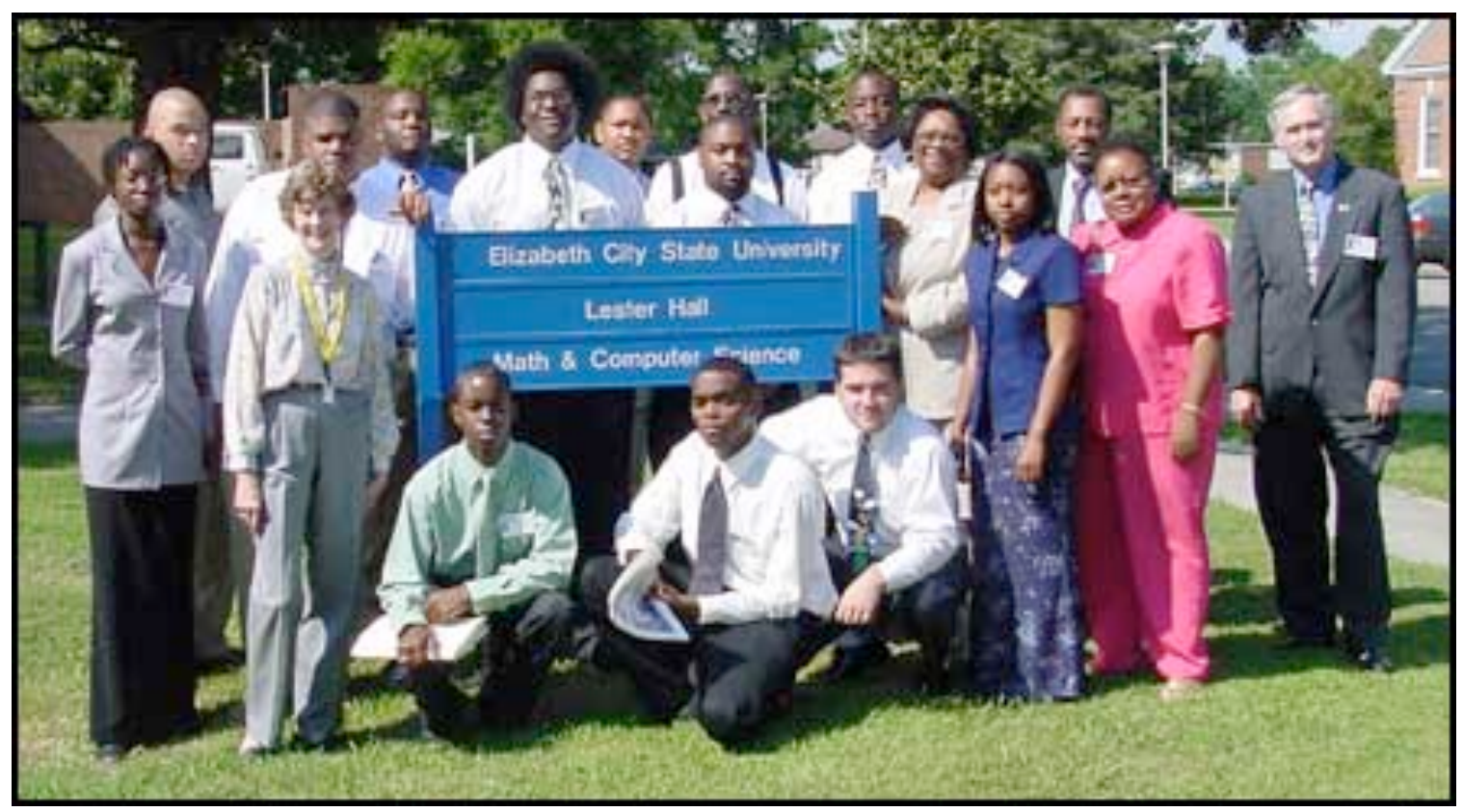

\section{Earth Science collaborations}

Support for partnerships between research and non-research institutions should be encouraged to produce high-quality scientists and engineers and improve the transition from undergraduate to graduate programs for underrepresented students (NSF 2004). Further, forming alliances with professional societies provide links to researchers, instructors, and learners (NSDL 2004). Efforts to build productive collaborations have resulted in best practice strategies which develop both the research training and professional development capabilities in underrepresented undergraduates enrolled in the academic year and summer research programs.

The Undergraduate Research Experience in Ocean and Marine Science Program (URE) was established through the Center of Excellence in Remote Sensing Education and Research (CERSER) in 2001. Since its inception, the URE program has focused on the professional development of underrepresented minority students through engagement in research involving the application of remote sensing techniques to ocean, coastal and marine environments. The program is conducted for eight weeks each summer with online follow-up activities during the academic year. Participants in the URE program are recruited through a national solicitation. The academic year mentoring program is conducted from September through April exclusively for students at Elizabeth City State University. The academic year program involves 20-25 students while the summer program involves 10-15 students.

Supporting both the academic year program and the summer program is a network of government agencies, minority and majority university faculty mentors. Identification 
of program participants is the primary responsibility of Elizabeth City State University personnel as well as the logistical arrangements required to support the programs.

Structured professional development activities and research training activities provide mentors, increased oral and written communication skills. Association with both faculty mentors and distinguished visiting lecturers are an integral part of the academic and summer experience. A detailed list of the professional development and research training activities that are an essential part of both' the academic year and summer programs follows.

Professional Development Activities

- Encourage and support membership in professional societies

- Encourage and support research presentations at appropriate venues

- Require attendance at seminars and visiting lectures

- Require participation in scientific writing and GRE preparation workshops

- Encourage and support internship on-campus and off-campus

- Require frequent oral and written reports

- Celebration of accomplishments through awards and acknowledgements

- Encourage and support graduate school aspirations

Research Training Activities

- Organizing teams of 2-5 other undergraduates and one or more mentors

- Mentor supervision of problem definition, data collection and analysis

- Provide training on appropriate software and hardware

- Require review of the scientific literature

- Organize and support Next-level mentoring of pre-college students by undergraduates, undergraduates by graduates.

An example of a supporting collaboration is the summer 2004 Stennis Research Center partnership which resulted in a pilot study undertaken to determine the spatial and temporal variability of chlorophyll concentrations in the northwestern Gulf of Mexico during 2002. The chlorophyll parameter was obtained from daily Level-3 estimations of Sea-Viewing Wide-Field-of-view Sensor (SeaWiFS) data computed by the Naval Research Laboratory. An empirical eigenfunction (EOF) analysis was performed on the data using the Karhunen-Loeve (KL) algorithm. Ten empirical eigenfunctions, temporal coefficients, and variance spectrum were computed. This analysis revealed that $15 \%$ of the variance around the mean is accounted by the first empirical eigenfunction, which is identified with chlorophyll fluctuations around the Mississippi Delta, Lakes Pontchartrain and Borgne, the Mississippi Sound, and the Mobile, Pensacola, and Choctawhatchee Bays. The eigenfunction shows that the chlorophyll in near-shore water is changing more rapidly than the rest of the shelf waters. The second EOF which contained $3 \%$ of the variance is found to be related to changes in chlorophyll in bays and estuaries to the east of the delta, exclusively. The third EOF (\%) was identified with the waters flowing east from the mouth of the Mississippi into bays and estuaries. The fourth EOF (\%) is identified with changes in chlorophyll concentrations at the mouth of the Mississippi River proper, propitiated by the river flow. Because this EOF is also identified with waters of Lakes Pontchartrain and Borgne as well as with the Mississippi Sound, it is 
possible that the changes observed may not be related to chlorophyll but to increases in dissolved and particulate components brought about by an increase in rain fall. The investigation was conducted by a team of two undergraduate students, one faculty from ECSU and one Stennis Researcher. This project was particularly successful because the students felt that there were an integral part of a real research project with the potential to contribute in a significant way to the knowledge base of the spatial and temporal variability of chlorophyll concentrations in the northwestern Gulf of Mexico

Numerous other remote sensing research team projects have been conducted as a result of collaborations between minority, majority institutions and government agencies during the academic year and summer programs. These include but are not limited to The Effects of Wind Speed and Direction on Both Sea Surface Temperature and Strandings of Harbor Porpoise; Dolphin Behavior Correlation with SST; Detecting Coastal Upwelling Events Along the NC Coast Utilizing AVHRR and In-Situ Sea Surface Temperatures and Wind Data; and Remote Sensing of Turbidity and Water Clarity in the Atlantic Ocean with the use of SeaWiFS Data.

Results from the academic year research training program indicate that $78 \%$ of the students who went on to graduate school from ECSU from 1993 through 2004 have participated in the research training program which is supported by collaborations focused on enhancing undergraduate involvement in remote sensing applications to earth science research (Hayden, Wilkins 2004).

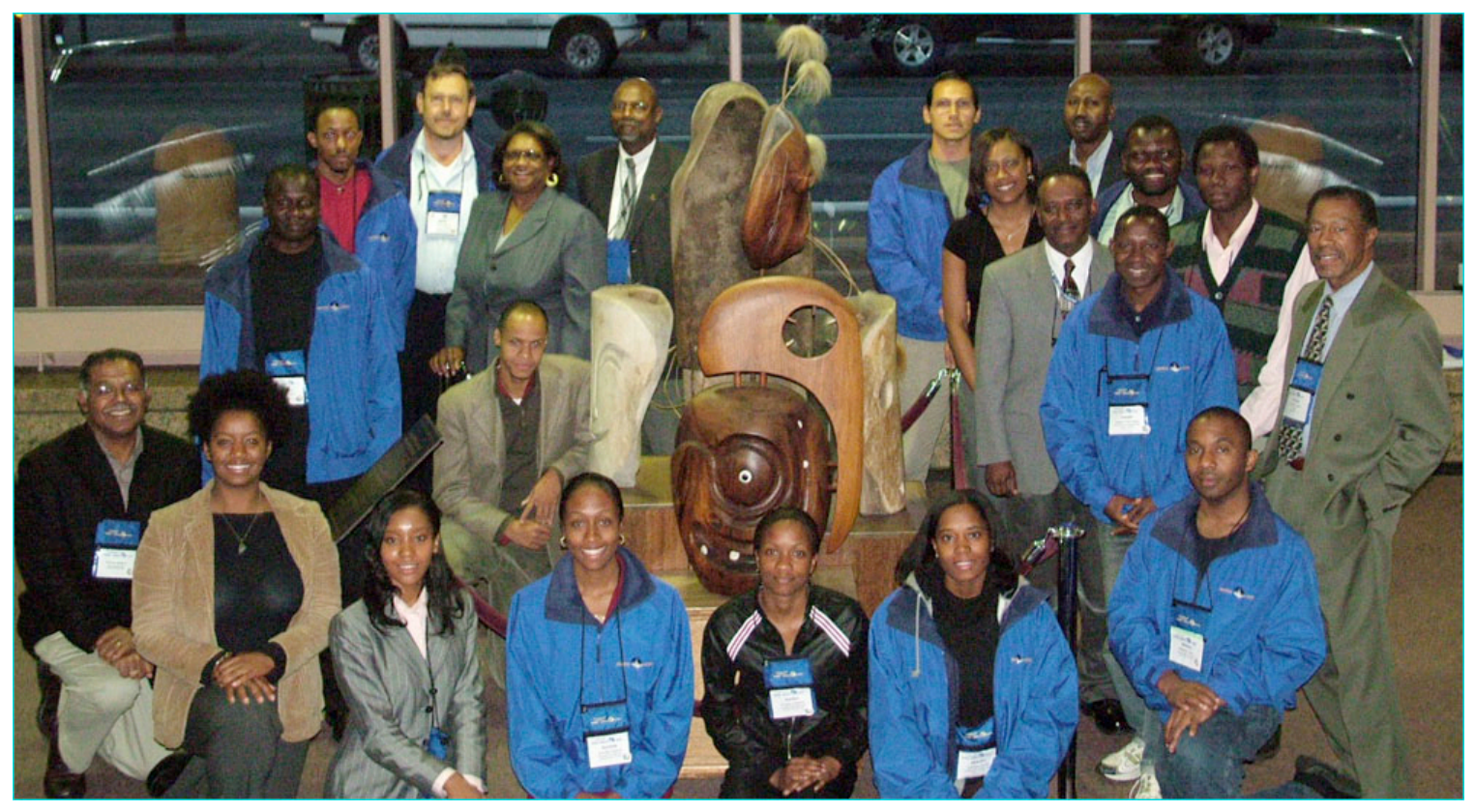

Atmospheric Science collaborations

The first collaboration with NASA LaRC involved Validation of LITE Tropospheric and Stratospheric Temperature Measurements. The Lidar-In-SpaceTechnology-Experiment (LITE) was flown on the STS-64 in September of 1994. LITE was the first lidar developed to fly in Earth's orbit and perform atmospheric studies. The LITE mission had three major objectives: validate instruments for operational spaceborne lidars, explore as many applications of spaceborne lidars as possible, and gather 
information on the range and variability of cloud, aerosol, and surface return signals for use in designing future systems. LITE used a Nd:YAG laser operating at three channels $1064 \mathrm{~nm}, 532 \mathrm{~nm}$, and $355 \mathrm{~nm}$ to study Earth's lower atmosphere.

During this investigation the NASA LaRC mentor and team used a single scatter lidar equation to investigate tropospheric and stratospheric aerosol and temperature measurements derived from the 355 and $532 \mathrm{~nm}$ channels. Temperature Profiles of 355 $\mathrm{nm}$ channel were compared to coincident balloonsonde measurements between 5 and $40 \mathrm{~km}$. The $355 \mathrm{~nm}$ channel temperature profiles were corrected for aerosol scattering using the $532 \mathrm{~nm}$ channel and an assumed Angstrom coefficient. The RMS between the corrected profiles and the balloonsonde data were computed. Subsequent investigations supported through the LaRC collaboration involved students from Hampton University in Validation of SABER Temperature Measurements Using Ground-based Instruments and The Accuracy of SAGE III: Comparing limb scattering measurements.

Techniques used to enhance undergraduate involvement in remote sensing applications to atmospheric research includes:

1) Identification of research subjects which will hold the interest of the students

2) Training of the students to use state of the art tools for atmospheric studies

3) Pairing up the students with compatible Faculty and Scientists

4) Defining research programs and goals that are critical to the mission so that students are cognizant of the importance of the work

5) Setting a goal of disseminating the results in refereed journal papers or public fora such as the AGU and IGARSS annual symposia

6) Providing sufficient guidance for the students to pursue graduate studies or professional career in Atmospheric Sciences and Remote Sensing

One of the areas HU students have made a significant contribution to aerosol science is through the use of the lidar backscatter measurements to identify aerosol types. This has also provided invaluable education for $\mathrm{HU}$ students in remote sensing and atmospheric sciences. One of the student graduates of this program wrote up his work for a publication in the Journal for Geophysical Research in which he identified classes of polar stratospheric clouds hitherto unknown to the community. His work was accepted for publication and is currently undergoing final revisions. The underlying paradigm in the success of the partnership between Elizabeth City State University, NASA Langley Research Center, Hampton University, Stennis Space Center, and The Office of Naval Research in fostering the development of undergraduate students at minority institutions is the identification of real research projects that lead to papers and conference presentations. This approach has kindled an interest in Atmospheric Sciences and Remote Sensing that could only have been latent because of lack of exposure. We hope to continue this effort until the numbers of underrepresented minorities are raised to acceptable levels. We are beginning to see these results as the improvements are quite discernible from year to year.

References

NSF, Committee on Equal Opportunities in Science and Engineering, Broadening Participation in America's Science and Engineering Workforce, December 2004 
The National Science Digital Library 2004 Annual Report Highlighting Successful Strategies for Growth.

Hayden, L., Broadening Participation in Science and Engineering, 2005, National Science Foundation HRD/Joint Annual Meeting, April 25- 26, 2005 Washington, DC

Hayden, L , Harrison-Wilkins, K. Mentoring Minority Undergraduates Through Remote Sensing and Geo-Information Science Research, African Association of Remote Sensing of the Environment (AARSE) 2004 bi-annual conferences, Oct. 18-21, 2004 Nairobi Kenya

Hayden, L., Walters, K., Identifying an Important Source of Talented Students from Underrepresented Communities Through Effective Partnerships with Minority Serving Institutions, AGU San Francisco, CA 2004

Wake, C., Hayden, L, "Building a Model of Research and Education Collaboration Between Minority and Majority Universities,” AGU Fall Meeting, San Francisco, 6 Dec 2005.

Jearld, A., Hayden, L., Interagency Collaborations with Universities to offer Interdisciplinary Training in Remote Sensing, Ocean and Marine Sciences, IEEEGeoscience and Remote Sensing Society IGARSS Conference, Seoul, Korea, July 2005 